\title{
Study of the Influence of the Intrinsic Parameters of Charcoal Pellets and Relative Humidity on Compressive Strength and Moisture Adsorption
}

\author{
Philippe Bernard Himbane ${ }^{1}$, Lat Grand Ndiaye ${ }^{1}$, Alfredo Napoli ${ }^{2}$ and Jean-François Rozis ${ }^{3}$ \\ 1. Department of Physics, the University Assane Seck of Ziguinchor, Ziguinchor 27000, Senegal \\ 2 Department of Persyst, Cirad Montpellier, Montpellier 34398, France \\ 3. Free Lance Expert, Montpellier 34070, France
}

\begin{abstract}
In this study, charcoal fines mixed with wheat starch or arabic gum were used to produce pellets. Moisture adsorption increased greatly by increasing relative humidity. Moisture adsorption depends also on the binder type used. All charcoal pellets had compressive strength above $1.0 \mathrm{MPa}$ and their moisture adsorption reached $3 \%$ to $12 \%$ depending on relative humidity conditions. In authors' experiment field, statistical analysis showed that binder type and the rate of binder had more significant effects on compressive strength. The moisture adsorption was more influenced by relative humidity and binder type.
\end{abstract}

Key words: Charcoal fines, binder, compressive strength, moisture adsorption and statistical analysis.

\section{Introduction}

The use of wood and charcoal as household cooking fuels poses serious environmental issues in many countries, particularly in developing countries. Deforestation is being more important. The increase of Senegalese population places more energy supply, to the extent that the increase use of these traditional fuels exposes the country to more pressure on natural forests and more human health negative impacts. According to the national survey, around 6 million cubic meters of wood are consumed as cooking fuel each year in Senegal [1]. In addition, according to statistical data from the World Health Observatory, 7,904 deaths recorded in Senegal in 2016 have been attributed to household air pollution [2] by use of biomass cooking fuel. To address these various challenges, coal briquettes can be one of the alternatives fuels. In recent years, vegetable coal briquettes have been identified as fuel substitute for

Corresponding author: Philippe Bernard Himbane, Ph.D., research fields: science of materials, biomass and energy. wood and lump charcoal in order to reduce the problems of deforestation and the emission of toxic pollutants [3, 4]. Considered as green fuels, their use should have much less problems than those from traditional fuels. However, these are sometimes subject to external solicitations, during transport, loading and storage operations, thus causing breakage, moisture adsorption, crumbling.

To enlarge their dissemination, those alternative cooking fuels have to respect minimal standards namely ability to resist to mechanical strength during transport and loading and reduced moisture absorption for maintaining high combustion quality.

Previous studies showed that the addition of binder like starch, arabic gum, molasse, had effects on physical and mechanical properties of coal briquettes $[5,6]$.

The purpose of this study is to determine compressive strength and moisture adsorption of charcoal pellets. This study makes it possible, among other things, to have an idea about the factors that most influence compressive strength and moisture adsorption. 

Humidity on Compressive Strength and Moisture Adsorption

To do this, moisture adsorption and mechanical compressive tests were carried out on charcoal pellets based on wheat starch and arabic gum for different levels of binder, compressive pressure and relative humidity.

\section{Experimental Setup}

In this study, moisture content and calorific value of charcoal fines were respectively $3 \%$ and $30.02 \mathrm{MJ} / \mathrm{kg}$.

\subsection{Preparation of Pellets}

Charcoal was crushed and sieved to obtain a granulometry of $1 \mathrm{~mm}$. Charcoal pellets were prepared by adding wheat starch and arabic gum as binders. Two levels of binder rate were used $(6 \%$ and $10 \%$ in dry basis). Binders of wheat starch and arabic gum were obtained by mixing wheat starch or arabic gum with water. A ratio of binder/water equal to 0.1 was used. The solution obtained was heated until a viscous solution was obtained (around $70^{\circ} \mathrm{C}$ ). Charcoal pellets used were produced by compressing $2 \mathrm{~g}$ of sample through $13 \mathrm{~mm}$ die diameter (see Fig. 1). A compressive testing machine (ADAMEL Lhomargy DY 36-DY36D MTS) was used and pressures of $20 \mathrm{MPa}$, $30 \mathrm{MPa}$ and $50 \mathrm{MPa}$ were applied by a piston with a diameter of $275 \mathrm{~mm}$ at a constant speed of $0.05 \mathrm{~mm} / \mathrm{s}$.

\subsection{Compressive Strength and Moisture Adsorption of Charcoal Pellets}

The tests conducted in order to determine the compressive strength of charcoal pellets were also performed by using the compressive testing machine (ADAMEL Lhomargy DY 36-DY36D MTS). The tests were based on applying a compressive load until

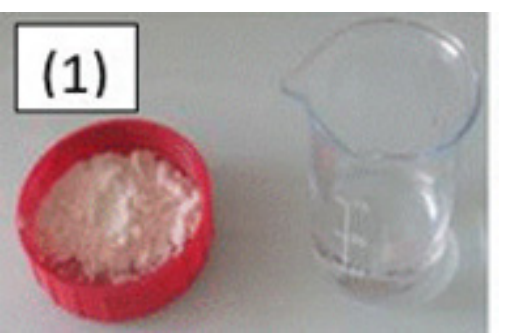

$6 \mathrm{~g}$ to $10 \mathrm{~g}$ of binder and $30 \mathrm{ml}$ to $50 \mathrm{ml}$ of water

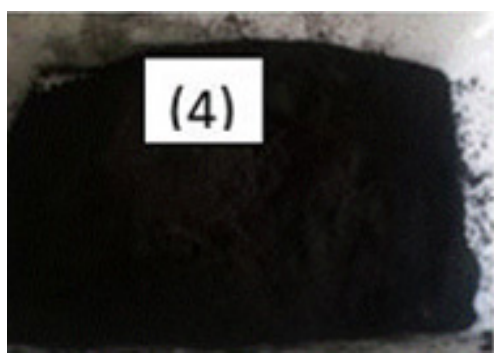

$90 \mathrm{~g}$ to $94 \mathrm{~g}$ of fines charcoal

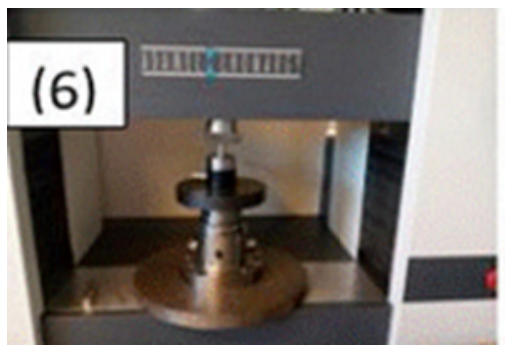

Pellet production

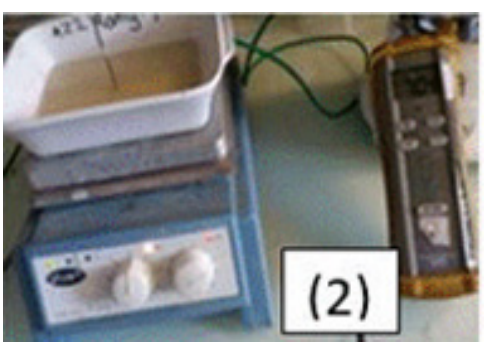

Preparation of the binder solution
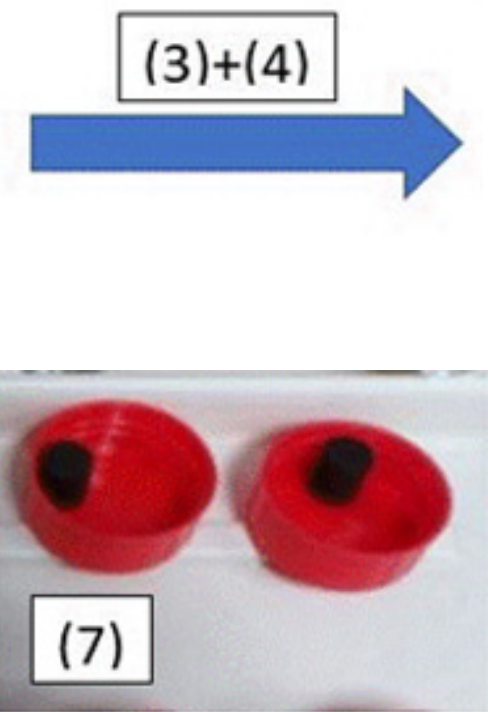

Pellet obtained

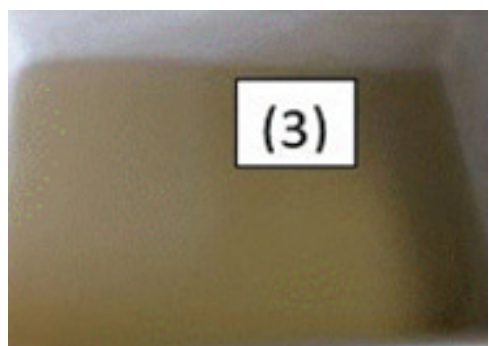

Solution of binder

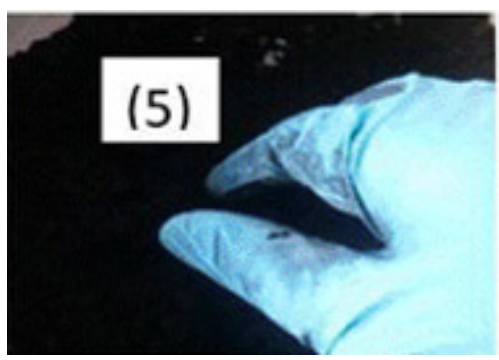

Mixing of fines charcoal and binder solution

Fig. 1 Scheme showing the different steps of pellets production. 
the structure of the charcoal pellet failed [7]. The axial compressive strength is given by:

$$
\sigma=\frac{F_{\max }}{S}
$$

where $F_{\max }(\mathrm{N})$ is the maximum load and $S\left(\mathrm{~mm}^{2}\right)$ the section of the charcoal pellets.

For moisture adsorption tests, a Memmert oven was used by applying the following parameters: temperature and relative humidity. The applied temperature was $30{ }^{\circ} \mathrm{C}$ and values of relative humidity were $30 \%, 65 \%$ and $85 \%$. The sample is weighted every 24 hours until its mass becomes constant. When equilibrium is reached, the moisture adsorption, $m_{a}$ is calculated by the Eq. (2):

$$
m_{a}=\frac{m_{e q}}{m_{i}}
$$

where $m_{e q}$ is the mass of the sample at equilibrium and $m_{i}$ the dry mass of the sample.

\subsection{Statistical Analysis}

Statistical analysis was performed, using experimental designs, to determine the factors that have the greatest influence on the compressive strength and the moisture adsorption. STATISTICA software (version 13.3.704.20) was used for the analysis. STATISTICA offers a wide range of tools for statistical analysis, management and graphical representation of data. It includes in its database several options among which we can mention that of the plans of experiments. A plan of experiments allows analysing a phenomenon in a methodical way. The method of the plans of experiments is a safe, practical and indispensable tool for conducting a study involving many parameters with the best possible efficiency: limited time, reduced costs, increased accuracy and improved reliability.

\section{Results}

\subsection{Axial Compressive Strength}

Compressive tests were performed on all produced charcoal pellets. The compressive test results of the pellets made with $10 \%$ of wheat starch and $10 \%$ of arabic gum, are respectively shown in Figs. 2 and 3. In the different figures, maximum points were observed on every compressive curve. These points correspond to the axial compressive strength, strength from which the sample loses its structure. As we observe in Figs. 2 and 3 , the compaction pressure and the type of binder influence the compressive strength. So, it will be interesting to know if these influences are significant or not; that is why statistical analysis was conducted.

All compressive tests results are shown in Table 1. Table 1 indicates all parameters of briquettes production and the compressive strength of every charcoal pellet.

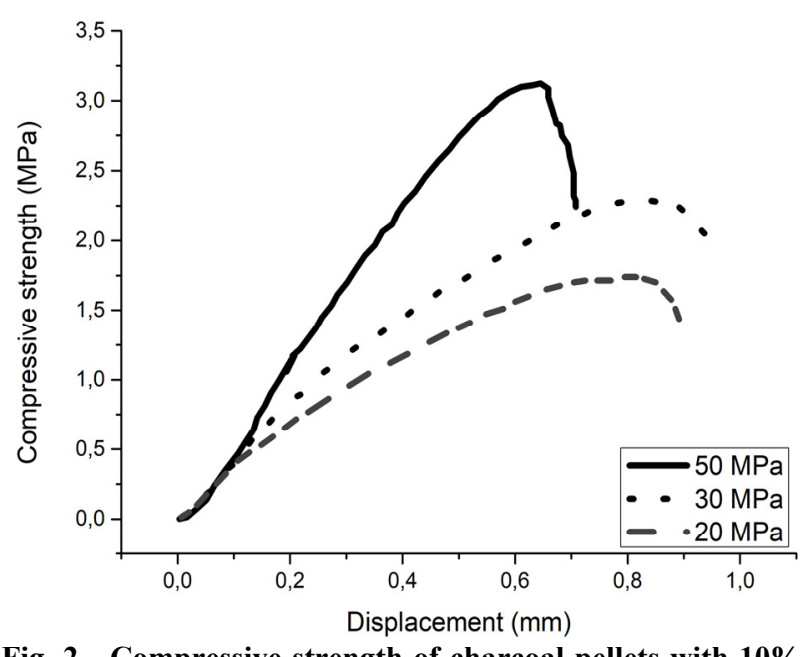

Fig. 2 Compressive strength of charcoal pellets with $10 \%$ of wheat starch.

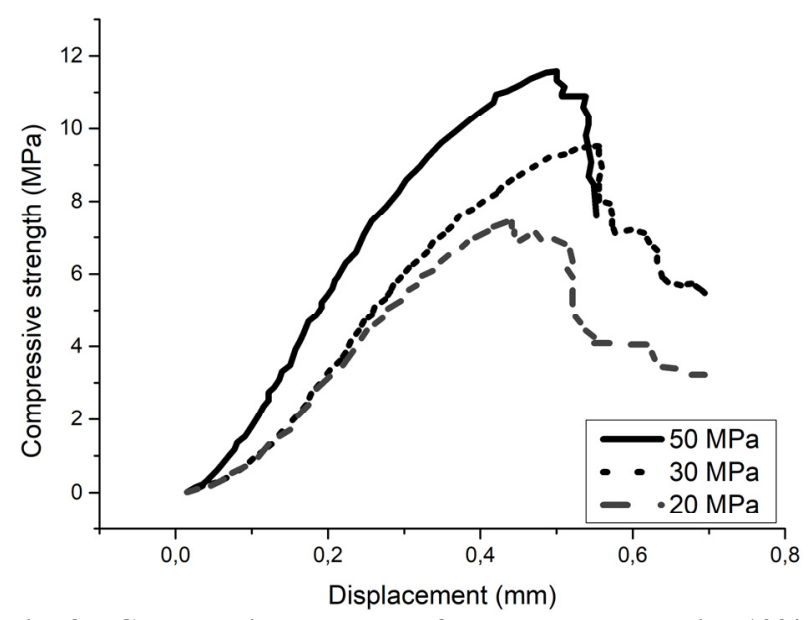

Fig. 3 Compressive strength of charcoal pellets with $10 \%$ of arabic gum. 

Humidity on Compressive Strength and Moisture Adsorption

Table 1 Compressive strength of charcoal for different conditions of briquettes production.

\begin{tabular}{llll}
\hline Independent variables & & Compaction pressure (MPa) & Compressive strength (MPa) \\
\hline Binder type & Binder rate (\%) & 20 & 2.70 \\
\hline Arabic gum & 6 & 30 & 3.18 \\
Arabic gum & 6 & 50 & 4.04 \\
Arabic gum & 6 & 20 & 7.14 \\
Arabic gum & 10 & 30 & 9.55 \\
Arabic gum & 10 & 50 & 11.56 \\
Arabic gum & 10 & 20 & 1.23 \\
Wheat starch & 6 & 30 & 1.55 \\
Wheat starch & 6 & 50 & 1.78 \\
Wheat starch & 6 & 20 & 1.79 \\
Wheat starch & 10 & 30 & 2.33 \\
Wheat starch & 10 & 50 & 3.14 \\
Wheat starch & 10 & & \\
\hline
\end{tabular}

The results showed that the more the rate of binder and the compaction pressure increased, the more the compressive strength was important. Charcoal pellets with arabic gum had the better compressive strength compared to those produced with wheat starch. According to the study of Borowski, et al. [8], the minimum compressive strength value, for briquettes with better quality, should be above 1.0 MPa. Ramaroson, et al. [9] found compressive strength of $1.25 \mathrm{MPa}$ with coal briquettes made of $6 \%$ cassava starch and compaction pressure equal to $39.8 \mathrm{MPa}$. Białowiec, et al. [10], Demirbas [11], Deniz [12] and $\mathrm{Hu}$, et al. [13] found that the compressive strength increased with increasing the rate of binder and compaction pressure. Deniz [12] found also that compressive strength decreased with compaction pressures from $60 \mathrm{MPa}$ to $150 \mathrm{MPa}$ and with addition of lime from $2.5 \%$ to $10 \%$.

\subsection{Moisture Adsorption}

Charcoal pellets, obtained in the same conditions than charcoal pellets used for compressive tests, were also used to perform moisture adsorption tests in different atmospheres at fixed temperature of $30{ }^{\circ} \mathrm{C}$ and relative humidity of $30 \%, 65 \%$ and $85 \%$. The results of these tests, for charcoal pellets with $10 \%$ of wheat starch and charcoal pellets with $10 \%$ of arabic gum, are indicated in Figs. 4 and 5.

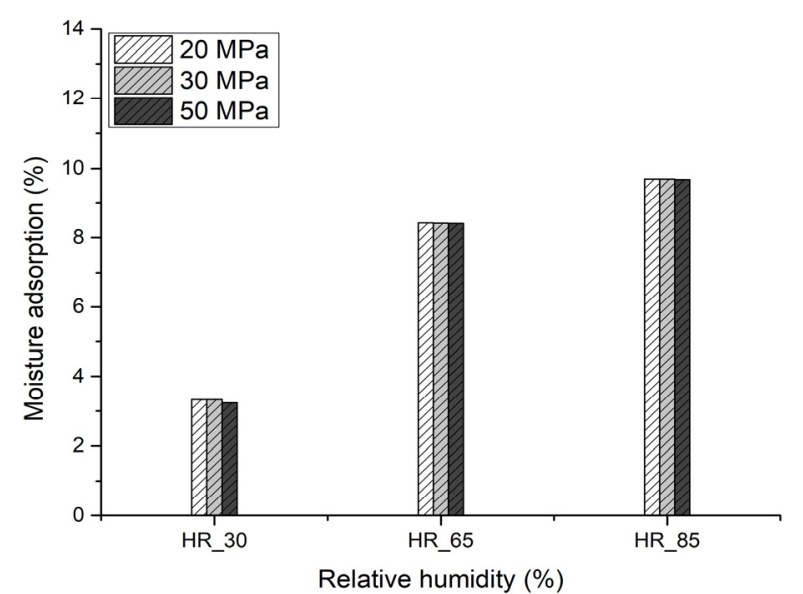

Fig. 4 Moisture adsorption of charcoal pellets with $10 \%$ of wheat starch.

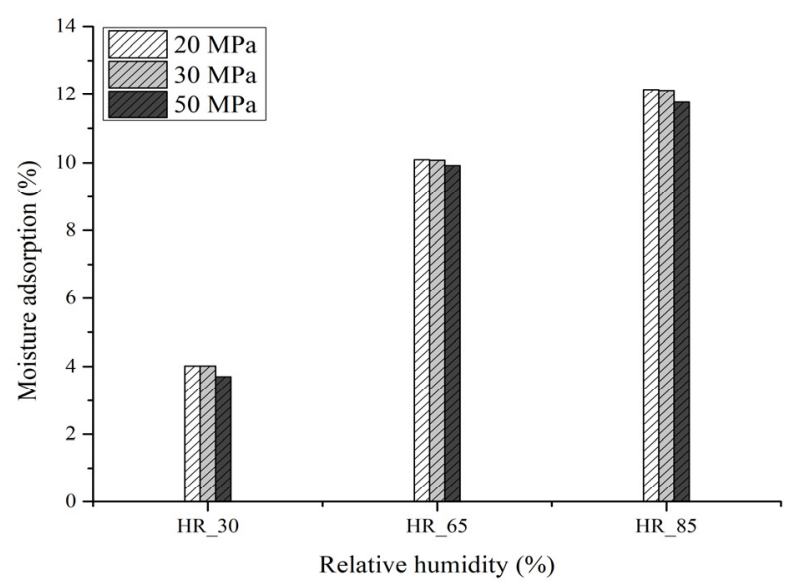

Fig. 5 Moisture adsorption of charcoal pellets with $10 \%$ of arabic gum.

As observed in Figs. 4 and 5, moisture adsorption is mainly influenced by relative humidity. It is evident. 
Humidity on Compressive Strength and Moisture Adsorption

Table 2 Moisture adsorption tests results.

\begin{tabular}{|c|c|c|c|c|}
\hline Binder type & $\begin{array}{l}\text { Binder rate } \\
(\%)\end{array}$ & $\begin{array}{l}\text { Compaction pressure } \\
(\mathrm{MPa})\end{array}$ & $\begin{array}{l}\text { Relative humidity } \\
(\%)\end{array}$ & $\begin{array}{l}\text { Moisture adsorption } \\
(\%)\end{array}$ \\
\hline Wheat starch & 6 & 20 & 30 & 3.63 \\
\hline Wheat starch & 6 & 20 & 65 & 8.70 \\
\hline Wheat starch & 6 & 20 & 85 & 10.00 \\
\hline Wheat starch & 6 & 30 & 30 & 3.73 \\
\hline Wheat starch & 6 & 30 & 65 & 8.89 \\
\hline Wheat starch & 6 & 30 & 85 & 10.12 \\
\hline Wheat starch & 6 & 50 & 30 & 3.67 \\
\hline Wheat starch & 6 & 50 & 65 & 8.97 \\
\hline Wheat starch & 6 & 50 & 85 & 10.12 \\
\hline Wheat starch & 10 & 20 & 30 & 3.33 \\
\hline Wheat starch & 10 & 20 & 65 & 8.43 \\
\hline Wheat starch & 10 & 20 & 85 & 9.70 \\
\hline Wheat starch & 10 & 30 & 30 & 3.33 \\
\hline Wheat starch & 10 & 30 & 65 & 8.42 \\
\hline Wheat starch & 10 & 30 & 85 & 9.70 \\
\hline Wheat starch & 10 & 50 & 30 & 3.23 \\
\hline Wheat starch & 10 & 50 & 65 & 8.42 \\
\hline Wheat starch & 10 & 50 & 85 & 9.68 \\
\hline Arabic gum & 6 & 20 & 30 & 3.05 \\
\hline Arabic gum & 6 & 20 & 65 & 8.70 \\
\hline Arabic gum & 6 & 20 & 85 & 10.25 \\
\hline Arabic gum & 6 & 30 & 30 & 4.10 \\
\hline Arabic gum & 6 & 30 & 65 & 9.90 \\
\hline Arabic gum & 6 & 30 & 85 & 11.47 \\
\hline Arabic gum & 6 & 50 & 30 & 4.02 \\
\hline Arabic gum & 6 & 50 & 65 & 9.84 \\
\hline Arabic gum & 6 & 50 & 85 & 11.40 \\
\hline Arabic gum & 10 & 20 & 30 & 4.02 \\
\hline Arabic gum & 10 & 20 & 65 & 10.09 \\
\hline Arabic gum & 10 & 20 & 85 & 12.14 \\
\hline Arabic gum & 10 & 30 & 30 & 4.02 \\
\hline Arabic gum & 10 & 30 & 65 & 10.08 \\
\hline Arabic gum & 10 & 30 & 85 & 12.12 \\
\hline Arabic gum & 10 & 50 & 30 & 3.70 \\
\hline Arabic gum & 10 & 50 & 65 & 9.94 \\
\hline Arabic gum & 10 & 50 & 85 & 11.97 \\
\hline
\end{tabular}

It was also observed that the type of binder influences the moisture adsorption of charcoal pellets. It seems that compaction pressure had no significant effect on moisture adsorption. Statistical analysis (cf. part statistical analysis) was performed to verify if influences are significant or not. Table 2 indicates the results of moisture adsorption tests and the independent variables (type of binder, rate of binder, compaction pressure and relative humidity).
Moisture adsorption increased considerably by increasing the relative humidity from $30 \%$ to $85 \%$. The maximum value (12.14\%) of moisture adsorption was observed for charcoal pellets with arabic gum. It was observed that the moisture adsorption of charcoal pellets with arabic gum increases with the increase of the rate of arabic gum. For charcoal pellets with wheat starch, we observed that moisture adsorption decreases with increasing the rate of binder. These 
variations of moisture adsorption of charcoal pellets with wheat starch are in contrary of those found by $\mathrm{Hu}$, et al. [14].

Moisture adsorption reached $3 \%$ to $12 \%$ by increasing relative humidity from $30 \%$ to $85 \%$, depending on the binder used. $\mathrm{Li}$, et al. [15] found, by working with a relative humidity of $75 \%$ at $30{ }^{\circ} \mathrm{C}$, that the dried low rank coal tends to equilibrate at the moisture content of approximately $13 \%$.

\subsection{Statistical Analysis}

The aim of this part was to verify, on the one hand, the influence of binder type, the rate of binder and compaction pressure on compressive strength, and on the other hand, the influence of relative humidity and the factors listed above (type of binder, rate of binder and compaction pressure) on the moisture adsorption. So, data obtained from compressive and moisture adsorption tests were submitted to statistical analysis. The module "experimental design" of STATISTICA software was used for the analysis. The tests of analysis of variance (ANOVA) were made. The test of ANOVA is used to determine if the effect of a factor on the response is significant. A low value of probability ( $p$-value) allows saying if a factor is significant or not. A factor will be considered as significant if its $p$-value is inferior to 0.05 . During the tests, the type of binder, the rate of binder, the compaction pressure and the relative humidity were replaced by factors respectively coded as $X_{1}, X_{2}, X_{3}$ and $X_{4}$. Tables 3 and 4 respectively show the results of the significance test of factors $X_{1}, X_{2}, X_{3}$ and $X_{4}$ on compressive strength and the moisture adsorption.

For compressive strength, the results of the tests of ANOVA showed that the type of binder and the rate of binder had statistically significant influences. Their $p$-values were inferior to 0.05 . The effect of the type of binder on compressive strength was more important. The results showed also that the effect of compaction pressure was not statistically significant. In addition to the effect of the relative humidity, the effect of the type of binder on moisture adsorption was also statistically significant.

The linear models without interaction between factors did not allow a good correlation between the values observed and the values predicted. By considering the interactions between factors, two models of prediction were proposed. These models are represented by the following equations.

For compressive strength:

$$
\begin{aligned}
Y_{1}=-831.1+ & 8,08429 X_{1}+133.839 X_{2} \\
& +6,36738 X_{3}-0.00149583 X_{3} X_{3} \\
& -1.3025 X_{1} X_{2}-0.0616786 X_{1} X_{3} \\
& +0.0154018 X_{2} X_{3}
\end{aligned}
$$

Table 3 Significance test of factors $X_{1}, X_{2}$ and $X_{3}$ on compressive strength.

\begin{tabular}{llllll}
\hline Factors & Sum of square & $\begin{array}{l}\text { Degree of } \\
\text { freedom }\end{array}$ & Mean square & $F$-value & $p$-value \\
\hline Type of binder, $X_{1}$ & 57.8602 & 1 & 57.86021 & 16.32145 & 0.004933 \\
Rate of binder, $X_{2}$ & 36.8551 & 1 & 36.85508 & 10.39623 & 0.014566 \\
Compaction pressure, $X_{3}$ & 7.3355 & 2 & 3.66776 & 1.03462 & 0.403967 \\
Error & 24.8153 & 7 & 3.54504 & & \\
Total & 126.8661 & 11 & & & \\
\hline
\end{tabular}

Table 4 Significance test of factors $X_{1}, X_{2}, X_{3}$ and $X_{4}$ on moisture adsorption.

\begin{tabular}{llllll}
\hline Factors & Sum of square & $\begin{array}{l}\text { Degree of } \\
\text { freedom }\end{array}$ & Mean square & $F$-value & $p$-value \\
\hline Type of binder, $X_{1}$ & 9.7552 & 1 & 9.7552 & 37.667 & 0.000001 \\
Rate of binder, $X_{2}$ & 0.0860 & 1 & 0.0860 & 0.332 & 0.568793 \\
Compaction pressure, $X_{3}$ & 0.6700 & 2 & 0.3350 & 1.293 & 0.289689 \\
Relative Humidity, $X_{4}$ & 332.2570 & 2 & 166.1285 & 641.456 & 0.000000 \\
Error & 7.5106 & 29 & 0.2590 & & \\
Total & 350.2788 & 35 & & & \\
\hline
\end{tabular}


where $X_{1}=102$ if the type of binder is arabic gum or $X_{1}=103$ if the type of binder is wheat starch.

For moisture adsorption:

$$
\begin{aligned}
Y_{2}=247.774 & -2.54873 X_{1}-24.5434 X_{2} \\
& +0.425167 X_{3}-0.0175275 X_{3} X_{3} \\
& -2,16588 X_{4}-0.00149535 X_{4} X_{4} \\
& +0.248333 X_{1} X_{2} \\
& +0.00012096 X_{1} X_{2} X_{3} \\
& +0.0241559 X_{1} X_{4} \\
& -0.0416806 X_{2} X_{3} \\
& +0.000506944 X_{2} X_{3} X_{3} \\
& +0.00182124 X_{2} X_{4}
\end{aligned}
$$

where $X_{1}=102$ if the type of binder is arabic gum or $X_{1}=101$ if the type of binder is wheat starch.

The two models proposed had respectively the coefficient of determination $\left(R^{2}\right)$ and the coefficient of determination adjusted $\left(R_{\text {adj }}^{2}\right)$ equal to 0.99282 and 0.98026 for compressive strength and 0.99673 and 0.99502 for moisture adsorption. These high coefficients of determination indicate a good correlation between the values observed and the values predicted in the limits of our experimental field. The correlations between the values observed and the values predicted are shown in Figs. 6 and 7.

Figs. 6 and 7 showed that the values of compressive strength and moisture adsorption were closed to the linear straight. That meant a good correlation between the values.

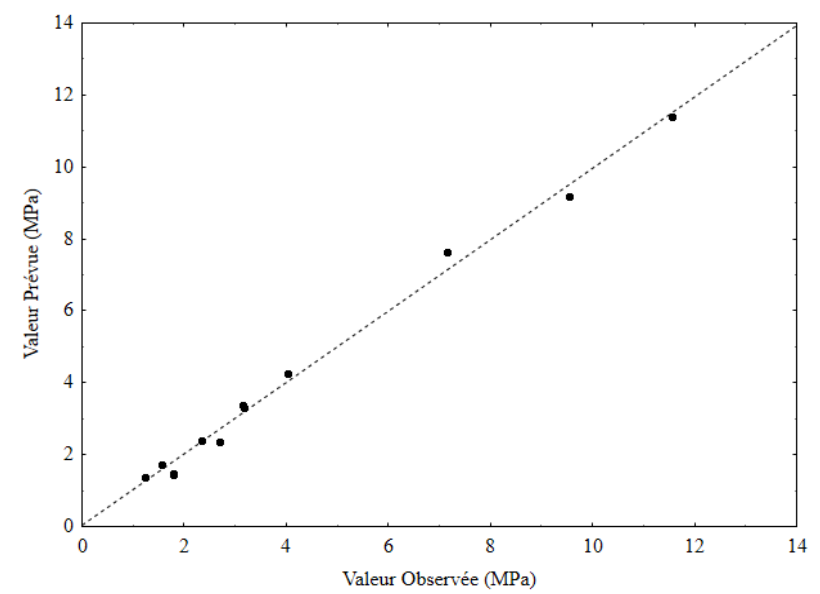

Fig. 6 The correlations between observed and predicted values of the compressive strength.

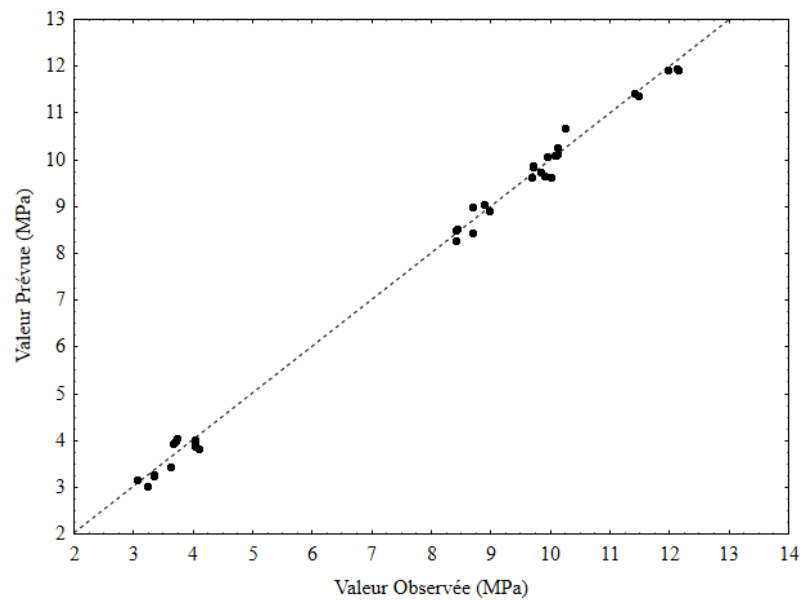

Fig. 7 The correlations between observed and predicted values of the moisture adsorption.

\section{Conclusion}

Wheat starch and arabic gum can be used as binders source to produce adequate compressive strength charcoal pellets (above 1.0 MPa). The addition of wheat starch as well as arabic gum results in a charcoal pellet with compressive strength respectively of $1.23 \mathrm{MPa}$ and $11.56 \mathrm{MPa}$ when compaction pressure is between $20 \mathrm{MPa}$ and $50 \mathrm{MPa}$ and the rate of binder between $6 \%$ and $10 \%$. When charcoal pellets are stored in atmosphere of $65 \%$ of relative humidity, their moisture content can reach $10 \%$. Statistical analysis showed that compressive strength could be more improved by increasing the rate of binder or choosing a good binder than changing the binder or increasing compaction pressure. To reduce moisture adsorption, attention will be paid in the choice of the binder.

\section{Acknowledgement}

The AUF (Agence Universitaire de la Francophonie) and the French cooperation support this work.

\section{References}

[1] PROGEDE-2. 2014. "Deuxième projet de gestion durable et participative des énergies traditionnels et de substitution: Promotion et diversification des énergies domestiques modernes (enquête nationale)." Sénégal. (in French) 

Humidity on Compressive Strength and Moisture Adsorption

[2] World Health Organization. 2018. Global Health Observatory Data Repository. Accessed September 16, 2018.

http://apps.who.int/gho/data/node.main.BODHOUSEHO LDAIRDTHS?lang=en.

[3] Li, Q., Qi, J., Jiang, J., Wu, J., Duan, L., Wang, S., and Hao, J. 2019. "Significant Reduction in Air Pollutant Emissions from Household Cooking Stoves by Replacing Raw Solid Fuels with Their Carbonized Products." Science of The Total Environment 650: 653-60.

[4] Qi, J., Li, Q., Wu, J., Jiang, J., Miao, Z., and Li, D. 2017. "Biocoal Briquettes Combusted in a Household Cooking Stove: Improved Thermal Efficiencies and Reduced Pollutant Emissions." Environmental Science \& Technology 51: 1886-92.

[5] Manyuchi, M. M., Mbohwa, C., and Muzenda, E. 2018. "Value Addition of Coal Fines and Sawdust to Briquettes Using Molasses as a Binder." South African Journal of Chemical Engineering 26: 70-3.

[6] Sen, R., Wiwatpanyaporn, S., and Annachhatre, A. P. 2016. "Influence of Binders on Physical Properties of Fuel Briquettes Produced from Cassava Rhizome Waste." International Journal of Environment and Waste Management 17: 158.

[7] Borowski, G. 2011. "Possibilities of Utilization of Energy Briquettes." Electrical Engineering Research Report 1: 48-51.

[8] Borowski, G., Stępniewski, W., and Wójcik-Oliveira, K. 2017. "Effect of Starch Binder on Charcoal Briquette
Properties." International Agrophysics 31: 571-4.

[9] Ramaroson, J. de D., Andrianaivoravelona, J. O., Rakotosaona, R., Rasoanaivo, J. L., Andrianary, P., Andrianaivo, L., and Ratsimbazafy, H. M. 2015. "Etude de la transformation du charbon de terre de la Sakoa en combustible domestique." MADA HARY 3:105-30. (in French)

[10] Białowiec, A., Micuda, M., and Koziel, J. 2018. "Waste to Carbon: Densification of Torrefied Refuse-Derived Fuel." Energies 11: 1-20.

[11] Demirbas, A. 1999. "Properties of Charcoal Derived from Hazelnut Shell and the Production of Briquettes Using Pyrolytic Oil." Energy 24: 141-50.

[12] Deniz, V. 2013. "Production of Water-Resistant Briquettes from a Mixture of an Imported Bituminous Coal and a Turkish Lignite with Copolymer Binder." International Journal of Coal Preparation and Utilization 33: 26-35.

[13] Hu, Q., Yang, H., Yao, D., Zhu, D., Wang, X., Shao, J., and Chen, H. 2016. "The Densification of Bio-Char: Effect of Pyrolysis Temperature on the Qualities of Pellets." Bioresource Technology 200: 521-7.

[14] Hu, Q., Shao, J., Yang, H., Yao, D., Wang, X., and Chen, H. 2015. "Effects of Binders on the Properties of Bio-Char Pellets." Applied Energy 157: 508-16.

[15] Li, X., Song, H., Wang, Q., Meesri, C., Wall, T., and Yu, J. 2009. "Experimental Study on Drying and Moisture Re-adsorption Kinetics of an Indonesian Low Rank Coal." Journal of Environmental Sciences 21: S127-30. 